\title{
The Use of Intravenous Amiodarone in the Acute Therapy of Life-Threatening Tachyarrhythmias
}

\author{
Alan Kadish and Fred Morady
}

$\mathbf{O}^{\mathrm{v}}$ VER THE PAST several years oral amiodarone has been shown to be effective for a wide variety of supraventricular and ventricular arrhythmias. ${ }^{1-15} \mathrm{~A}$ unique aspect of amiodarone therapy is the long time required to reach maximum efficacy. ${ }^{16-18}$ For example, Rakita and Sobol used continuous ambulatory electrocardiographic monitoring to compare several different oral regimens for amiodarone loading and found that between 9.5 to 16.9 days were required for control of ventricular ectopy. ${ }^{16}$ Kadish et al demonstrated that the electrophysiologic effects of amiodarone differed at two weeks and 3 months, implying that the maximum effects of amiodarone were not present after two weeks of oral therapy. ${ }^{18}$

A prolonged time to maximum clinical efficacy may have important implications in certain groups of patients. The natural history of spontaneous arrhythmias is highly variable. Some patients may have infrequent episodes of arrhythmia and long arrhythmia-free intervals. In these patients, oral amiodarone may be an appropriate agent. In contrast, other patients may have frequent recurrences of life-threatening arrhythmias or incessant tachycardias unresponsive to direct countershock. In these patients, rapid antiarrhythmic efficacy is important, and therefore oral amiodarone by itself may not be adequate therapy.

There is evidence that amiodarone administered intravenously (IV) may have a rapid onset of action. Thus, IV amiodarone may be potentially useful in the therapy of patients with frequent or incessant arrhythmias. In addition, there may be patients with severe systemic illnesses in whom IV therapy may be the only method available for delivering an antiarrhythmic agent. This article will review the mechanisms of action of IV amiodarone, its pharmacokinetics and pharmacodynamics, some general considerations in its use, and the published clinical experience concerning its efficacy in the treatment of arrhythmias.

\section{MECHANISMS OF ACTION}

Many antiarrhythmic agents may have more than one mechanism of action. However, amio- darone is unique in that several basic and clinical sludies have demonstrated a wide variety of disparate pharmacologic actions that may contribute to its antiarrhythmic efficacy (Table 1). Amiodarone was initially developed as an antianginal agent. When early studies recognized that amiodarone may have antiarrhythmic efficacy, experimental studies were performed to determine its mechanism of action. ${ }^{19}$ Studies performed by Charlier, Singh, and other investigators in the $1970 \mathrm{~s}^{19-21}$ suggested that amiodarone prolonged action potential duration in both atrial and ventricular muscle but had relatively little effect on the maximum rate of rise of the action potential ( $\left.\dot{V}_{\max }\right)$ at clinically relevant pharmacologic concentrations. The drug therefore was classified as a Type III antiarrhythic agent in the Vaughn-Williams classification. ${ }^{22}$

Subsequent studies have demonstrated that amiodarone in fact does prolong action potential duration in atrial and ventricular muscle during both acute and chronic therapy, but that the absence of an effect of amiodarone on action potential upstroke in earlier studies probably was a function of slow stimulation frequencies. ${ }^{23-25}$ Stimulation frequency may affect antiarrhythmic drug activity. A certain degree of tonic block may be present at rest and at more rapid stimulation frequencies, because of greater drug binding, larger effects may occur. Hongdehem and Katzung developed the modulated receptor hypothesis to explain binding of antiarrhythmic agents. ${ }^{26,27}$ This hypothesis states that the sodium channel can exist in three different statesresting, activated, or inactivated. The resting state of the sodium channel occurs at resting membrane potential in the absence of stimulation. With depolarization, the channels enter the active state and remain open during the upstroke. Sodium channels then enter the inactivated state

From the Cardiology Division, Department of Internal Medicine, University of Michigan, Ann Arbor.

Address reprint requests to Fred Morady, MD. Professor of Internal Medicine, Division of Cardiology, 1500 E Medical Center Dr, B1-F245-0022. Ann Arbor, MI 48109.

(c) 1989 by Grune \& Stratton, Inc.

0033-0620/89/3104-0002\$5.00/0 
Table 1. Pharmocoligic Effects of Amiodarone

Prolongation of action potential duration in atrial and ventricular muscle.

Blockade of inactivated sodium channels and use dependent decrease in $\mathrm{V}$ max.

Decrease in phase 4 automaticity in the sinus node.

Slow channel blockade.

Interaction with the thyroid axis - block of $T_{4}$ to $T_{3}$ effect on nuclear receptors.

Hemodynamic effects

Peripheral and coronary vasodilitation

Decrease in contractility

Noncompetitive $\alpha-\beta$ blockade in a variety of experimental preparations.

during the plateau phase of the action potential or when cells are partially depolarized, such as by ischemia. A drug that binds equally to all states of the sodium channel would have no use-dependent effect. Mason et $\mathrm{al}^{23-24}$ demonstrated that amiodarone blocks inactivated sodium channels, in contrast to Type IA antiarrhythmic agents that by and large bind to activated sodium channels. The binding and unbinding of amiodarone to inactivated sodium channels leads to a significant use-dependent depression in the maximum upstroke velocity ( $\dot{\mathrm{V}} \max )$ of the action potential. The use-dependent effect of amiodarone has been confirmed by Yabek et $a 1^{25,28}$ and other investigators. The clinical implication of this finding is that at slow heart rates, amiodarone's predominant electrophysiologic effect may be to prolong the action potential duration, whereas during a tachycardia, significant amiodarone binding to cardiac sodium channels is likely to occur, resulting in use-dependent depression of $\dot{V} \max$. The prolongation of action potential duration induced by amiodarone may potentiate its effects on $\dot{V} \max$ by increasing the time which sodium channels spend in the inactivated state and thus increasing drug binding. This may result in slowing of conduction in ventricular muscle. Accordingly, Morady et $\mathrm{al}^{29.30}$ demonstrated a cycle lengthdependent increase in QRS duration with both IV and oral amiodarone. Not all cardiac cells are equally susceptible to amiodarone's lengthening of action potential duration. Yabet $e^{28}$ reported that amiodarone increases action potential duration in Purkinje fibers but has no effect on action potential duration in the rabbit sinus node.
In addition to prolonging action potential duration and decreasing the upstroke velocity of the action potential in a use-dependent fashion, amiodarone has a wide variety of other electrophysiologic effects (Table 1). Amiodarone has been shown to slow phase 4 depolarization in the rabbit sinus node $e^{28,31,32}$ and to slow conduction in the canine atrio-ventricular (AV) node. ${ }^{32}$ This suggests that amiodarone may block calcium channels in the AV junction. In addition, amiodarone is a vasodilator and has negative inotropic effects. These hemodynamic effects may evoke autonomic reflexes that alter electrophysiologic parameters. Amiodarone also has been shown to display an unusual type of noncompetitive alpha and beta sympathetic blockade in a variety of experimental preparations. ${ }^{19,33,34}$ It has been suggested that the sympathetic blocking activity may occur more quickly than the other effects of amiodarone. Finally, a unique interaction exists between amiodarone and the thyroid system. Both hypothyroidism and hyperthyroidism have been reported as a side effect of amiodarone and amiodarone produces an almost universal increase in reverse $T_{3}$ concentration. ${ }^{35,36}$ Because some electrophysiologic effects of hypothyroidism are similar to those of amiodarone, it has been hypothesized that a major mechanism of action of amiodarone involves antagonism of thyroid hormone. Since some of the thyroid antagonism appears to be mediated via effects on the thyroid gland itself, these effects may require days to weeks to develop. In addition, desethyl amiodarone but not amiodarone displaces $\mathrm{T}_{3}$ from thyroid nuclear receptors. ${ }^{37}$ To the extent that antagonism of thyroid hormone action may be important in amiodarone's efficacy, one would expect that IV amiodarone may have different electrophysiologic effects than chronic oral therapy. However, more recent studies have suggested that the interaction of amiodarone with thyroid hormone may be less important than previously thought. For example, Polikar et al ${ }^{38}$ showed that administration of $T_{3}$ to seven patients did not abolish amiodarone's antiarrhythmic efficacy. Meese et $\mathrm{a}^{39}$ showed that iopanoic acid, which inhibits conversion of $T_{4}$ to $T_{3}$ and thus causes an increase in reverse $T_{3}$ concentration similar to amiodarone, had no antiarrhythmic or electrocardiographic effects. 


\section{PHARMACOKINETICS AND \\ PHARMACODYNAMICS OF \\ INTRAVENOUS AMIODARONE}

Therapy with IV medications may differ in several ways from chronic oral therapy. Intravenous bolus administration of a drug results in the rapid onset of a high serum concentration that then decreases over time because of either excretion, metabolism, or redistribution. Andreasen et $\mathrm{al}^{40}$ found that a $400 \mathrm{mg}$ bolus of amiodarone resulted in concentrations of greater than 10 $\mu \mathrm{g} / \mathrm{mL}$ which declined to below $1 \mu \mathrm{g} / \mathrm{mL}$ after approximately one to two hours. Metabolism may account for a small portion of the decrease in concentration after an IV bolus. Only one amiodarone metabolite-desethyl amiodaronehas been reliably identified in patients receiving amiodarone therapy. ${ }^{36}$ The time course of conversion has not been analyzed in detail, but three to five days are required to achieve plasma concentrations of desethyl amiodarone similar to those of amiodarone. ${ }^{41}$ Similar concentrations persist during long-term therapy. ${ }^{18}$ Little amiodarone is excreted in the urine acutely. In fact, several studies have not been able to demonstrate any drug in the urine after a single dose of amiodarone. ${ }^{42-43}$ Tissue distribution accounts for most of the decay in plasma concentrations after a single IV dose. Adipose tissue takes up amiodarone avidly and results in tissue concentrations greater than 100 times that in blood after both oral and IV therapy. ${ }^{44,45}$ Other tissues including lung, liver, pancreas, and thyroid also have concentrations several times that in blood. Myocardial concentrations of amiodarone and desethyl amiodarone are also high with accumulation ratios of from 20 to $260 .{ }^{46}$ Latini, Connolly, and Kates $^{47}$ examined myocardial uptake of amiodarone after a single IV bolus and found a peak myocardial level of $>10 \mu \mathrm{g} / \mathrm{mL} 10$ to 30 minutes after an initial bolus. The mean ratio of tissue to blood cooncentrations was 89. All studies of the pharmacokinetics of IV amiodarone have demonstrated an extremely high volume of distribution (ranging from 1.3 to $65.8 \mathrm{~L} / \mathrm{kg}$ ) $40,42,48,49$ and a large total blood clearancc.

Early studies of IV amiodarone demonstrated a terminal half-life that was far shorter than that after chronic oral therapy, ranging from 4.3 to 17.4 hours. However, these studies involve extra- polations of blood concentration and did not include measurements of serum concentration after approximately 40 hours. Using more sensitive techniques, Holt et al were able to show measurable concentrations of amiodarone and desethyl amiodarone persisting up to 58 days after a single $400 \mathrm{mg}$ bolus. ${ }^{48}$ They showed a long terminal elimination phase with an average halflife of 25 days similar to a long washout time present after chronic oral administration. In summary, amiodarone is rapidly redistributed to body tissues after a single IV bolus, is metabolized over several days to desethyl amiodarone to produce an approximately one-to-one ratio of drug to metabolite, and possesses an extremely long terminal elimination half-life.

Despite the rapid achievement of high plasma levels and significant pharmacologic activity with IV amiodarone, stable electrophysiologic effects may require days to weeks to develop. ${ }^{15,18}$ Several mechanisms for the delayed onset of stable activity have been proposed. Some investigators have compared the pharmacologic actions of amiodarone and desethyl amiodarone in an attempt to determine if differing pharmacologic actions of desethyl amiodarone may be responsible for the delayed onset of action of amiodarone. ${ }^{28,50}$ Talajic, DeRoode, and Nattel gave single IV doses of 10 to $25 \mathrm{mg} / \mathrm{kg}$ of amiodarone or desethyl amiodarone to anesthesized dogs. Amiodarone had quantitatively greater effects on Wenckebach cycle length and thus, AV nodal conduction, whereas desethyl amiodarone produced larger increases in QRS duration and atrial and ventricular refractory periods. This suggested that desethyl amiodarone had relatively greater effects on fast channel tissue in vivo than did amiodarone, and could account for some of the delayed electrophysiologic effect in patients receiving long-term amiodarone therapy. In addition to effects of metabolites, the interaction of amiodarone with the thyroid axis may also require some time to stabilize. For example, reverse $T_{3}$ concentrations are not elevated after a single IV dose.

\section{HEMODYNAMICS OF INTRAVENOUS AMIODARONE}

Charlier described a dose related decrease of myocardial contractility in dogs treated with IV 
amiodarone. ${ }^{19}$ This suggested that either IV amiodarone or the solvent in which it was injected (Tween 80 ) produced negative inotropic effects. ${ }^{51}$ Several investigators have addressed this issue in clinical studies. Bopp et al studied ${ }^{52}$ 16 patients who received $5 \mathrm{mg} / \mathrm{kg}$ of IV amiodarone. They noted a $15 \%$ decrease in maximum $\mathrm{dp} / \mathrm{dt}$, a $12 \%$ decrease in left ventricular stroke work, and insignificant increases in pulmonary wedge and right atrial pressures. All their patients had coronary artery disease and most of them had normal baseline hemodynamics.

Kosinski et $\mathrm{al}^{53}$ separated patients into two groups based on their resting ejection fraction. Those patients with ejection fractions $>35 \%$ had a small but significant increase in cardiac index due predominantly to a decrease in systemic vascular resistence. However, patients with ejection fractions less than $35 \%$ experienced a drop in cardiac index from 2.1 to $1.7 \mathrm{~L} / \mathrm{min}$, a decrease in arterial pressure, and an increase in mean pulmonary artery pressure. They concluded that in patients with resting left ventricular dysfunction, the negative inotropic effect of amiodarone cannot be overcome by vasodilitation, and that the drug may worsen cardiac performance.

Remme et a ${ }^{54}$ infused $5 \mathrm{mg} / \mathrm{kg}$ of IV amiodarone over five minutes and measured hemodynamic changes during the infusion and five minutes later. They noted a decrease in left ventricular peak $\mathrm{dp} / \mathrm{dt}$ which persisted five minutes after the infusion. Left ventricular end diastolic pressure increased significantly and other measurements of myocardial performance were depressed as well. They concluded that IV amiodarone reduces vascular resistence and contractility. Schwartz et al ${ }^{55}$ studied 16 patients given IV amiodarone and noted a transient decrease in cardiac index that returned to control values within one hour except in two patients with severe left ventricular dysfunction. They did not demonstrate a significant change in systemic vascular resistance.

In summary, IV amiodarone appears to have a negative inotropic effect. In patients with normal cjection fractions, the effect is minor and largely compensated for by vasodilitation such that myocardial performance is not affected in a major way. In the subgroup of patients with left ventricular dysfunction, IV amiodarone clearly can produce transient worsening of cardiac performance.

\section{ELECTROCARDIOGRAPHIC AND CLINICAL ELECTROPHYSIOLOGIC EFFECTS OF INTRAVENOUS AMIODARONE}

The effects of IV amiodarone on the surface electrocardiogram and on a variety of electrophysiologic parameters are described in Table 2. Amiodarone appears to prolong the PR interval in most studies, a finding that is consistent with experimental studies showing a major effect on AV nodal conduction. Most studies have shown no effect in QRS duration either in sinus rhythm or at a pacing cycle up to $600 \mathrm{~ms},{ }^{29}$ consistent with the observation that there is little effect on the rate of action potential upstroke at low stimulation frequencies. By and large no change in the QT interval has been observed with IV amiodarone administration; this is in sharp contrast to the effects of chronic oral therapy; however, Saksena et al ${ }^{56}$ demonstrated a significant increase in the corrected QT interval with IV administration of amiodarone. Sinus cycle length has also remained unchanged in most studies; however, Saksena et $a^{56}$ did demonstrate an increase in sinus cycle length from 754 to 860 ms.

Touboul et al $^{57}$ examined sinus cycle length, sinus node recovery time and sino-atrial conduction time in several patients. They found no change in sinus cycle length or sino-atrial conduction time but an increase in sinus node recovery time in 17 of 24 patients treated with amiodarone. Unlike chronic oral amiodarone therapy, IV amiodarone in a dose of $5 \mathrm{mg} / \mathrm{kg}$ has not been shown to prolong atrial or ventricular refractoriness in most studies. One study by Morady et al demonstrated a small but statistically significant increase in right ventricular refractory period after $10 \mathrm{mg} / \mathrm{kg}$ of IV amiodarone therapy. ${ }^{29}$ The $\mathrm{HV}$ interval has also remained unchanged in most studies. In contrast to the relatively minor effects in atrial and ventricular refractorincss, and His-Purkinje and intraventricular conduction times, major effects have been noted on the AV node. The AH interval increased significantly in all studies as did the refractory period of the AV node. Thus, the increase in PR interval seen with IV amiodarone is due to $\mathrm{AH}$ prolonga- 


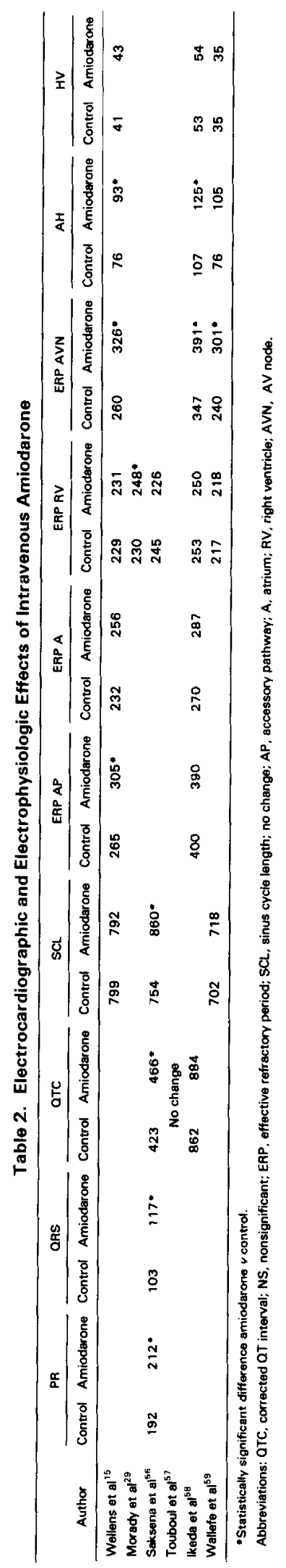


tion. The few studies that are available suggest that amiodarone also prolongs the effective refractory period of accessory pathways in the Wolff-Parkinson-White syndrome.

\section{CLINICAL EXPERIENCE WITH INTRAVENOUS AMIODAROONE}

Intravenous amiodarone has been used in both children and adults for the treatment of supraventricular and ventricular arrhythmias. The reports have been descriptive in nature and involved relatively small numbers of patients. No randomized or placebo controlled studies are available and criteria for success have been variable including termination of incessant spontaneous arrhythmia, suppression of frequent episodes of tachycardia, supression of inducibility at electrophysiologic testing and suppression of ambient ectopy.

Most studies have used an initial 5 to 10 $\mathrm{mg} / \mathrm{kg}$ bolus of IV amiodarone. ${ }^{15,60,61}$ In some cases, this bolus was administered in only one minute, ${ }^{15}$ whereas in others it was administered at a rate of $50 \mathrm{mg} / \mathrm{min}$. Several investigators have followed the bolus by an initial 50 to 100 $\mathrm{mg} / \mathrm{h}$ over the first 24 hours, whereas others evaluated efficacy after a single bolus. Another approach has been a continuous constant rate infusion over the first 12 hours. $^{62}$ The method of IV amiodarone dosing in individual studies are summarized in Tables 2 and 3. No studies comparing different rates of infusion of IV amiodarone have been published.

\section{SUPRAVENTRICULAR ARRHYTHMIAS}

Several studies have examined the use of IV amiodarone in treating a variety of supraventricular arrhythmias. ${ }^{15,59,63-69}$ In almost all cases the drug was infused during the tachycardia. The largest study of IV amiodarone for the treatment of supraventricular arrhythmias was performed by Storelli et al. ${ }^{65}$ They demonstrated $17 \%$ and $27 \%$ efficacy in small numbers of patients with atrial fibrillation and atrial flutter, respectively, but $88 \%$ efficacy at 15 minutes and $100 \%$ efficacy at one hour in paroxysmal supraventricular tachycardia. Other studies described in Table 3 also have demonstrated a relatively low efficacy rate in atrial fibrillation and atrial flutter and higher effectiveness for paroxysmal supraventricular tachycardia including atrio-ventricular reentrant tachycardia and various types of $\mathrm{AV}$ nodal reentry. A study by Wellens et al was the only report to demonstrate less than $50 \%$ efficacy in AV reentrant tachycardia in the WolffParkinson-White syndrome. ${ }^{15}$ A figure in their paper indicates that at least one of their patients had orthodromic supraventricular tachycardia, but the mechanism of the other tachycardias was not specified. It is unclear why a dose similar to that used in the other studies was successful in only a small percentage of cases. Although unsuccessful in terminating atrial flutter or atrial fibrillation, amiodarone did produce slowing of the ventricular rate in the majority of patients treated. The experience in the Wolff-ParkinsonWhite syndrome and AV nodal reentry suggests that AV nodal tissue is more sensitive to the acute effects of IV amiodarone than is working cardiac muscle. This is in agreement with the previously noted experimental study of Talajic. ${ }^{50}$ The relatively low efficacy in terminating atrial fibrillation and atrial flutter is in contrast to the efficacy of oral amiodarone in preventing recurrences of atrial fibrillation and atrial flutter.' This suggests either that atrial muscle is less sensitive to IV amiodarone than to chronic oral therapy or that the drug has a greater efficacy in preventing recurrences of atrial fibrillation and atrial flutter than in terminating the arrhythmia.

\section{AMIODARONE THERAPY FOR VENTRICULAR ARRHYTHMIAS}

Studies on the treatment of ventricular arrhythmias with amiodarone (Table 4) have involved either infusion of the drug during an arrhythmia episode, infusion in patients with frequent arrhythmia episodes, examination of the short-term clinical response, the use of Holter monitoring, or the use of electrophysiologic testing. There is little information on the ability of electrophysiologic testing after IV amiodarone to predict short-term outcome of therapy.

Horowitz et $\mathrm{al}^{61}{ }^{61} \mathrm{Leak}^{60}$ and Wellens et $\mathrm{al}^{15}$ infused amiodarone in a dose of 5 to $10 \mathrm{mg} / \mathrm{kg}$ during ventricular tachycardia. Horowitz et al ${ }^{61}$ and Leak et $a l^{60}$ reported success in five of five and two of two patients, respectively, whereas Wellens ${ }^{15}$ reported that amiodarone did not terminate ventricular tachycardia in any of the three patients in which it was tried. Two of these 
Table 3. Supraventricular Arrhythmias (Infusion During Arrhythmia)

\begin{tabular}{|c|c|c|c|c|c|c|c|}
\hline Author & Dosage & Arrhythmia & $\begin{array}{l}\text { Number } \\
\text { Treated }\end{array}$ & $\begin{array}{l}\text { Number } \\
\text { Successful }\end{array}$ & Side Effects & $\begin{array}{l}\text { Additional } \\
\text { Drugs }\end{array}$ & $\begin{array}{c}\text { Site } \\
\text { of Tachycardia } \\
\text { Termination }\end{array}$ \\
\hline Wellens et al ${ }^{15}$ & $5 \mathrm{mg} / \mathrm{kg} \times 1$ & $\begin{array}{l}\text { Atrio-ventricular } \\
\text { reentrant } \\
\text { (WPW) tachy- } \\
\text { cardia }\end{array}$ & 9 & 3 & 2 flushing & 0 & AVN \\
\hline Maggioni et al ${ }^{63}$ & $5 \mathrm{mg} / \mathrm{kg} \times 3$ & Uncommon AVNR & 1 & 1 & None & 0 & Retrograde slow \\
\hline Holt et al ${ }^{64}$ & $5 \mathrm{mg} / \mathrm{kg}$ & Atrial fibrillation & 7 & $1 *$ & $\begin{array}{l}\text { All flushing } \\
5 \text { nausea }\end{array}$ & 0 & \\
\hline \multirow[t]{3}{*}{ Storelli et al $^{65}$} & $300 \mathrm{mg}$ & PSVT & 33 & $29 / 331$ & 2 flushing & 0 & \\
\hline & $300 \mathrm{mg}$ & Atrial flutter & 11 & 3 & & 0 & \\
\hline & $300 \mathrm{mg}$ & Atrial fibrillation & 6 & 1 & & 0 & \\
\hline \multirow[t]{3}{*}{ Bucknall et al ${ }^{66}$} & $5-7 \mathrm{mg} / \mathrm{kg}$ & Atrial flutter & 1 & 1 & None & 0 & \\
\hline & & SVT & 1 & 1 & & 0 & \\
\hline & & $\begin{array}{l}\text { His Bundle tachy- } \\
\text { cardia }\end{array}$ & 1 & 1 & & 0 & \\
\hline Leak $^{60}$ & $\begin{array}{l}150 \mathrm{mg} \text { IVB then } \\
600 \mathrm{mg} \text { over } \\
24 \mathrm{~h}\end{array}$ & Atrial fibrillation & 4 & $2 / 4 \ddagger$ & None & 0 & \\
\hline \multirow[t]{2}{*}{ Gomes et $a^{67}$} & $5 \mathrm{mg} / \mathrm{kg}$ & AVNR & 7 & 7 & Mild Hypotension & & $\begin{array}{l}2 \text { Blocked retro- } \\
\text { grade, } 3 \text { blocked } \\
\text { antegrade }\end{array}$ \\
\hline & & Concealed BT & 2 & 2 & & & $\begin{array}{l}\text { Blocked retrograce } \\
\text { in } B T\end{array}$ \\
\hline Waleffe et $a^{b y}$ & $300 \mathrm{mg}$ & Concealed BT & 2 & 2 & & & $\begin{array}{l}\text { Blocked retrograde } \\
\text { in BT }\end{array}$ \\
\hline \multirow[t]{2}{*}{ Alboni et $a^{68}$} & 1 & Concealed BT & 14 & 8 & & & \\
\hline & & AVNR & 13 & 5 & & & \\
\hline \multirow[t]{3}{*}{ Installe et $\mathrm{al}^{69}$} & $2.5-5 \mathrm{mg} / \mathrm{kg}$ & Atrial fibrillation & 18 & 6 & $\begin{array}{c}\text { 5/94 severe hy- } \\
\text { potension } \oint\end{array}$ & & \\
\hline & & Atrial flutter & 14 & 3 & & & \\
\hline & & Atrial tachycardia & 16 & 8 & & & \\
\hline
\end{tabular}

* Patient returned to NSR one hour after bolus.

+29 effective at 15 minutes, 33 at one hour.

†Effective after several days of IV therapy.

§Postoperative treatment of a variety of arrhythmias. Figures represent side effects for the total group.

Abbreviations: NSR, normal sinus rhythm; AVNR, atrio-ventricular nodal reentry; PSVT, paroxysmal supraventricular tachycardia; BT, bypass tract; WPW, Wolff-Parkinson-White.

patients had significant slowing of the tachycardia cycle length.

Six studies ${ }^{56,70-73}$ have examined the ability of IV amiodarone to prevent spontaneous arrhythmia recurrences in patients with frequent episodes of sustained ventricular tachycardia. Apparent drug efficacy was noted in $50 \%$ to $80 \%$ of patients. However, not all the studies clearly documented the frequency of arrhythmia episodes before beginning IV amiodarone and thus, it is possible that some of the apparent efficacy of IV amiodarone was due to spontaneous variability in the frequency of episodes of ventricular tachycardia. Scheinman (personal communication, August 1,1987$)^{76}$ has collected the largest series of patients with sustained ventricular ar- rhythmias treated with amiodarone. Forty-six patients were treated, 16 of whom had incessant arrhythmias. Twenty-seven patients responded to IV amiodarone within 48 hours, 15 within the first two hours; an additional six patients responded to oral therapy. This large study demonstrated an impressive degree of efficacy in patients with drug resistant tachycardias. As with other antiarrhythmic agents, it is not clear if termination of an acute arrhythmia episode with IV amiodarone predicts that the drug will be successful in preventing spontaneous arrhythmia recurrences. Nonetheless, these small studies suggest that amiodarone can terminate acute episodes of ventricular tachycardia. Van Hoogenhuyze et $\mathrm{al}^{72}$ and Mostow et al ${ }^{62}$ exam- 


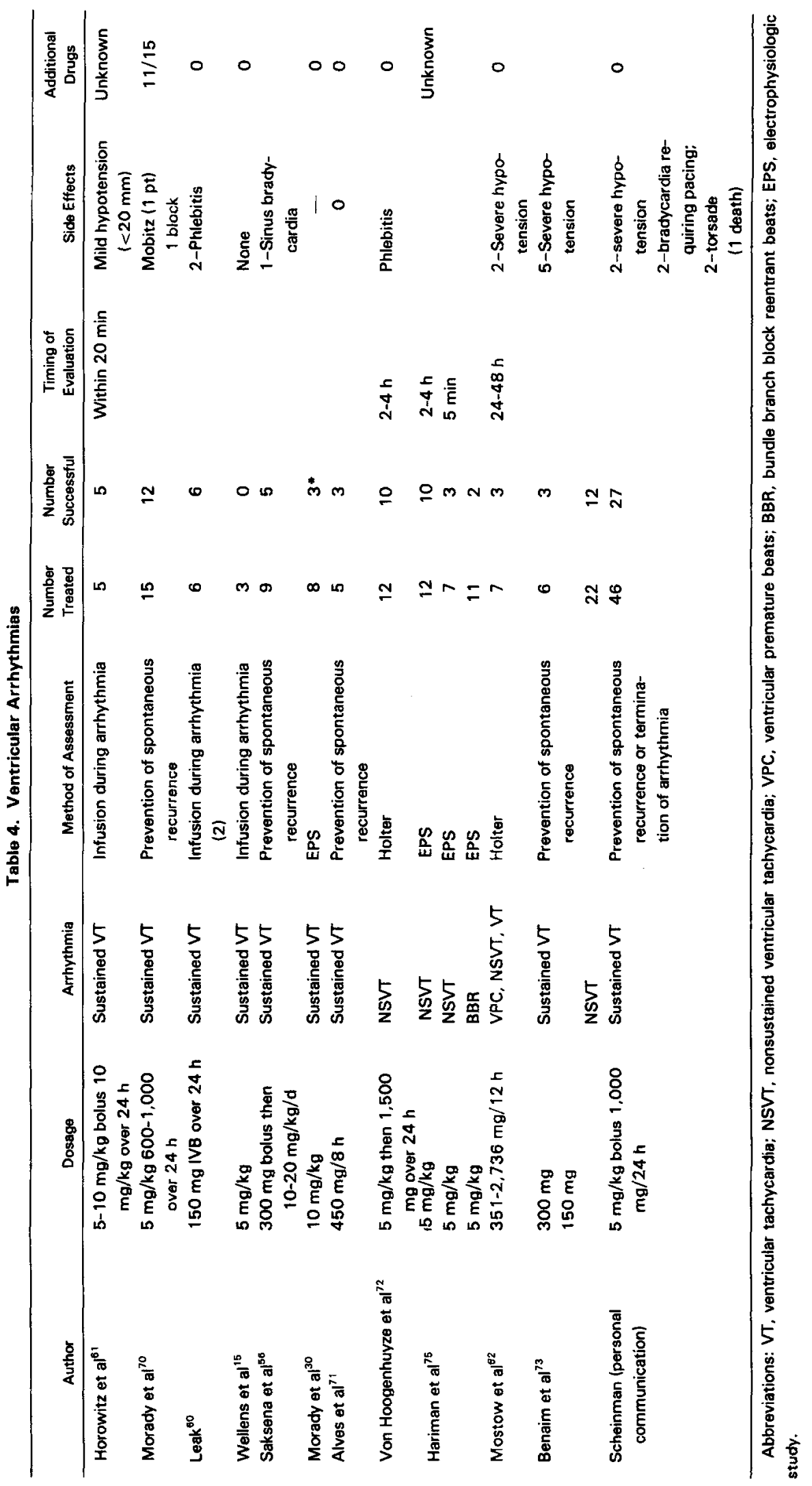


ined the ability of IV amiodarone to suppress spontaneous nonsustained ventricular tachycardia or ventricular ectopy. Mostow et a ${ }^{62}$ demonstrated a reduction in the frequency of nonsustained ventricular tachycardia, ventricular couplets, and ventricular premature beats in all seven patients and a complete suppression of nonsustained ventricular tachycardia in three of seven patients after two days of a continuous infusion of IV amiodarone. Van Hoogenhuyze et $\mathrm{al}^{72}$ reported that there was suppression of nonsustained ventricular tachycardia in ten of 12 paticnts and of couplcts in 13 of 16 patients. They evaluated their results after two to four hours of therapy. In contrast, a preliminary report of a study by Nadamanee et $\mathrm{al}^{74} \mathrm{did}$ not describe early premature ventricular contraction (PVC) suppression with IV amiodarone.

Morady et $a^{30}$ and Hariman ${ }^{75}$ examined the inducibility of ventricular tachycardia by programmed ventricular stimulation and after the administration of IV amiodarone. In patients with inducible sustained ventricular tachycardia studied approximately five minutes after the IV infusion, Morady et al found that three of eight patients and Hariman found that three of seven patients no longer had inducible sustained ventricular tachycardia. In addition, Hariman demonstrated efficacy for bundle branch reentrant bets in two of 11 patients and for nonsustained ventricular tachycardia in three of five patients.

Overall, these studies demonstrate that IV amiodarone has significant efficacy in terminating acute episodes of ventricular tachycardia, in preventing short-term recurrences in patients with frequent arrhythmia episodes, and for suppressing ambient nonsustained ventricular tachycardia and ventricular ectopy. Although most of the studies are relatively small, taken together they indicate an efficacy of over $50 \%$ in the acute treatment of ventricular arrhythmias.

\section{SIDE EFFECTS}

Major and minor side effects have been reported with the use of IV amiodarone. Transient hypotension of a relatively mild degree (less than $15 \mathrm{~mm} \mathrm{Hg}$ ) and flushing have been common in several studies. There is a suggestion that the higher incidence of flushing noted by some investigators ${ }^{15,64}$ may be due to a more rapid infusion (one minute) of an amiodarone bolus. Five patients in Holt's study also developed nausea ${ }^{64}$ Phlebitis has been relatively common in some studies and can be prevented by the use of a central venous catheter or a large gauge catheter located in the antecubital fossa.

Serious side effects have included conduction disturbances, severe hypotension, and congestive heart failure. Benaim et $\mathrm{l}^{75}$ reported infranodal block in two patients, Morady reported Mobitz one block in one patient, and Saksena ${ }^{56}$ reported sinus bradycardia in one patient. Veltri and Reid $^{76}$ observed sinus arrest during administration of IV amiodaronc in a patient. Bertholet et $\mathrm{al}^{77}$ reported marked QT prolongation with a corrected QT interval of 782 milliseconds 12 hours after beginning IV amiodarone. Intravenous amiodarone rarely may cause Torsade de Pointes. ${ }^{78}$

Although not common, severe hypotension and cardiogenic shock have been observed with amiodarone, presumably due to vasodilitation and a negative iotropic effect. Mostow et $a^{l^{62}}$ reported two patients who developed severe hypotension with the use of IV amiodarone. Hypotension was reversed with fluids, pressors, and discontinuation of the IV infusion in both patients. These patients subsequently tolerated oral therapy with amiodarone. Both of these patients had severely depressed left ventricular function with ejection fractions of $27 \%$ and $19 \%$, respectively, and there is a possibility that such patients may be more susceptible to hypotension with the use of IV amiodarone. Benaim and $\mathrm{Uzan}^{79}$ reported five cases of severe hypotension and one fatality among 153 patients treated with amiodarone. The French Registry of Cardiology found five deaths due to IV amiodarone that occurred after a bolus injection of an unspecified dose. No deaths occurred in patients who received a slow infusion. ${ }^{80}$ Thus rapid infusion of IV amiodarone has the potential of producing cardiogenic shock and even death in patients with left ventricular dysfunction.

\section{PREDICTION OF ORAL EFFICACY}

A question that arises in regard to the use of amiodarone is the possibility of continuing chronic oral amiodarone therapy after apparent success of the IV medication. Several studies have reported a discordance between the acute effects of IV amiodarone and chronic effects of 
oral drug therapy. Morady et a ${ }^{30}$ found that the induction of sustained ventricular tachycardia was suppressed in two of eight patients during electrophysiologic testing after IV amiodarone; both of these patients had inducible ventricular tachycardia during chronic oral amiodarone therapy two minutes later. Two different patients had only nonsustained ventricular tachycardia induced after oral amiodarone therapy even though they sustained ventricular tachycardia induced after IV infusion.

Saksena et $\mathrm{al}^{56}$ studied patients after four to scven days of 10 to $20 \mathrm{mg} / \mathrm{kg} / \mathrm{d}$ of IV amiodarone and subsequently after 24 to 53 days of oral therapy. Sixteen patients with inducible sustained and one patient with inducible nonsustained ventricular tachycardia were treated in this study. Several patients became noninducible after IV amiodarone therapy, but this noninducibility did not correlate with the ability to induce arrhythmias on chronic oral amiodarone therapy or with spontaneous arrhythmia recurrences. Wellens et $\mathrm{al}^{15}$ studied 12 patients, nine with the Wolff-Parkinson-White syndrome and three with ventricular tachycardia after an IV bolus of amiodarone and after approximately five to six weeks of chronic oral therapy. In patients with the Wolff-Parkinson-White syndrome there appeared to be some concordance between the effects of IV and oral amiodarone therapy. Three of nine patients had tachycardia terminated by IV amiodarone and had no inducible arrhythmia after IV amiodarone, and in two of these three patients arrhythmias remained noninducible after chronic oral amiodarone therapy. However, the degree of tachycardia slowing after oral amiodarone far exceeded that after IV amiodarone. The tachycardia cycle length was 340 milliseconds at control electrophysiologic study, 394 after IV amiodarone, and 441 after five to six weeks of oral amiodarone therapy. None of three patients with ventricular tachycardia had the tachycardia terminated or its induction prevented by IV amiodarone. However, one of these patients had the arrhythmia suppressed by chronic oral amiodarone therapy. Thus, an acute clinical response to IV amiodarone for either supraventricular or ventricular arrhythmias does not necessarily predict the chronic response. Conversely, Scheinman has found that six of 46 or $13 \%$ of patients who did not respond to IV amiodarone could be effectively treated with oral therapy. Studies in larger numbers of patients are required to determine whether the response to IV amiodarone has any predictive value in guiding chronic oral therapy.

\section{HIGH DOSE ORAL $\vee$ INTRAVENOUS LOADING}

Early studies in patients being treated with oral amiodarone at a maintenance dose of 200 to $400 \mathrm{mg} / \mathrm{d}$ indicated an extremely long time to the onset of maximum antiarrhythmic activity. Several investigators demonstrated that oral loading with 800 to $1400 \mathrm{mg} / \mathrm{d}$ shortens the amount of time required for arrhythmia control. However, approximately ten days are still required for the development of stable antiarrhythmic activity. Mostow et $\mathrm{al}^{81}$ has studied a very high dose oral loading protocol of 800 to $2,000 \mathrm{mg}$ two to three times per day and has demonstrated that PVC suppression occurred on the first day and a reduction in episodes of ventricular tachycardia began on the second day. By day two, four of eight patients with sustained ventricular tachycardia and six of ten patients with nonsustained ventricular tachycardia showed no ventricular tachycardia. The authors compared their experience using 1,600 to 4,400 $\mathrm{mg} / \mathrm{d}$ as a loading dose to two prior studies in which a conventional oral loading regimen or in which IV loading was used. They found that with high dose oral therapy, a mean of 3.6 days was required to reach efficacy as determined by Holter monitoring. This compares with their prior IV loading regimen in which a mean of 5.9 days was required and with conventional oral loading regimens in which a mean of 9.5 days was required. In order to minimize side effects, their IV loading regimen was based on a test dose and pharmacokinetic calculations to control the amount of amiodarone infused over a 12-hour period. They did not administer amiodarone cither as bolus or as a relatively rapid infusion of $50 \mathrm{mg} / \mathrm{min}$, as has been the case in other studies. They suggested that this minimized the risk of hypotension that may occur in patients with severe left ventricular dysfunction. However, in the studies that used rapid IV loading, antiarrhythmic effects were seen as early as five to ten minutes and appeared in all studies at two to four hours. In patients with recurrent symptomatic arrhythmias, the high dose oral loading regimen 
is relatively well tolerated (one patient developed a severe side effect involving orthostatic hypotension and cerebellia ataxia) and shortens the time of onset of drug action from approximately ten to three or four days; however, this may not be rapid enough in patients with incessant or frequent tachycardias. Although there may be some increase in toxicity using the rapid IV loading regimen, it has potential benefit for providing extremely rapid control of arrhythmias. Kerin et $\mathrm{al}^{82}$ compared, IV loading of amiodarone of a single dose of $500 \mathrm{mg} / \mathrm{kg}$ infused over 30 minutes followed by an oral loading regiment that was similar to the group treated with the oral loading regimen alone. The time to optimal arrhythmia control as defined by a $70 \%$ reduction of premature beats and $90 \%$ or greater reduction of couplets and abolition of ventricular tachycardia was $20 \pm 18$ days for the IV loading regimen $v$ $105 \pm 83$ days for the IV plus oral regimen. The authors in this study did not examine potential acute antiarrhythmic effects of IV amiodarone. Although the reasons for such a large discrepancy in the time to optimal control of ventricular arrhythmia with only a single $5 \mathrm{mg} / \mathrm{kg}$ dose of IV amiodarone are not entirely clear, the initial high blood levels obtained with a single IV dose could potentially saturate some body stores and account for a more rapid onset of maximum efficacy.

In summary, while high dose oral therapy may shorten the time to drug efficacy to three to four days, IV therapy may possess antiarrhythmic activity that occurs in less than one hour and may provide more immediate benefit.

\section{PATIENT SELECTION AND RECOMMENDATIONS}

Intravenous amiodarone is an effective agent for a wide variety of arrhythmias, but has the potential for causing hemodynamic collapse in patients with severe left ventricular dysfunction. The overall clinical experience indicates relatively good efficacy for nonsustained ventricular tachycardia and ventricular premature contractions, approximately $50 \%$ efficacy for incessant or recurrent sustained ventricular tachycardia, significant efficacy in termination of orthodromic supraventricular tachycardia in the Wolff-Parkinson-White syndrome, significant efficacy in terminating AV nodal reentry tachycardia and slowing of the ventricular response without arrhythmia termination in atrial fibrillation.

Intravenous amiodarone has not yet been approved for routine clinical use in the United States. Until more experience is gained it appears prudent to reserve the use of IV amiodarone for patients who have not responded to other antiarrhythmic agents, not so much because of the potential for immediate adverse reactions, but because it may commit a patient to chronic oral therapy with amiodarone. Because of the significant pulmonary, thyroid, neurologic, and dermatologic toxicity that may occur with longterm amiodarone therapy, it is preferable to avoid this drug if possible. ${ }^{12}$

Two groups of patients who have failed other drugs appear to be appropriate candidates for IV amiodarone therapy: those who are unable to tolerate oral drug therapy because of systemic illness and those who have incessant or frequent episodes of ventricular tachycardia in whom a rapid antiarrhythmic effect would be beneficial. Patients with infrequent arrhythmia episodes or only mildly symptomatic arrhythmias who have failed other drugs can be as effectively and more safely managed with standard or high dose oral loading with amiodarone.

Although the most appropriate method for judging the efficacy of antiarrhythmic agents is a subject of some controversy, the only issue which is relevant to the management of patients with frequent or incessant arrhythmias is distinguishing drug failure from drug induced worsening of arrhythmia. All antiarrhythmic drugs have the potential for worsening arrhythmia. ${ }^{83}$ Although Torsade de Pointes has been a well recognized result of drug toxicity, ${ }^{84}$ an increased frequency of nonsustained ventricular tachycardia or uniform sustained ventricular tachycardia also may be a result of antiarrhythmic agents. ${ }^{85}$ If a long QT interval and Torsade de Pointes are present, all antiarrhythmic medications should be discontinued and IV amiodarone should be withheld. A long QT interval and Torsade de Pointes should suggest that the problem is not drug failure, but drug toxicity. Because arrhythmias that are a result of antiarrhythmic drug therapy may be morphologically indistinguishable from those that are not, one should be certain that sustained arrhythmias are present in the drug frec statc and that their frequency has not been increased 
by antiarrhythmic medication before initiating therapy with IV amiodarone for incessant or frequent arrhythmias. If such data are not available, all other antiarrhythmic medications should be discontinued and the patient should be observed for several hours despite continuing arrhythmia before beginning IV amiodarone.

In patients without severe left ventricular dysfunction, rapid IV loading with 5 to $10 \mathrm{mg} / \mathrm{kg}$ of amiodarone given at $50 \mathrm{mg} / \mathrm{min}$ appears safe and effective. This can be followed with a continuous infusion of approximately $1,000 \mathrm{mg} / \mathrm{d}$. After arrhythmia control is achieved, patients can be placed on 1,400 to $2,000 \mathrm{mg} / \mathrm{d}$ of oral amiodarone for one to two weeks and then placed on an oral maintenance dose. In patients with severe left ventricular dysfunction (ejection fraction $<35 \%$ ), especially those who are already requiring inotropic medications for support, a slow continuous infusion of several hundred to several thousand milligrams over 12 hours as described by Mostow may be appropriate. ${ }^{62}$ However, when bolus administration of amiodarone is used, one can expect relatively rapid onset of at least some antiarrhythmic activity (in one hour or less), whereas this would not be the case with the slower continuous infusion. Thus bolus administration may be appropriate even in patients with left ventricular dysfunction who have incessant arrhythmias. Patients with left ventricular dysfunction who receive amiodarone should undergo careful hemodynamic monitoring and pharmacologic as well as mechanical inotropic support should be readily available.

An absence of a response to initial therapy with IV amiodarone in the first several hours does not preclude a short- or long-term beneficial response with continued IV or oral amiodarone therapy. Thus, if nonpharmocologic therapy of a particular arrhythmia is not appropriate in individual patients and other agents are not available, it is reasonable to continue IV and subsequently oral amiodarone with the hope that antiarrhythmic efficacy may be achieved.

In summary, although IV amiodarone possesses substantial antiarrhythmic activity, it is not yet approved by the Food and Drug Ad (FDA). Its use at this time should be reserved for patients who have failed other antiarrhythmic agents and who are either unable to tolerate oral therapy or who have frequent or incessant arrhythmias. In such patients it may be extremely useful and even a life-saving antiarrhythmic agent.

\section{REFERENCES}

1. Rosenbaum MB, Chiale P, Halpren MS, et al: Clinical Efficacy of amiodarone as an antiarrhythmic agent. Am J Cardiol 38:934-944, 1976

2. Hager JJ, Prystowsky EN, Jackman WM, et al: Amiodarone-Clinical efficacy and electrophysiology during longterm therapy for recurrent ventricular tachycardia or ventricular fibrillation. N Eng J Med 305:539-545, 1981

3. Nademanee K, Singh B, Hendrickson J, et al: Amiodarone in refractory life-threatening ventricular arrhythmias. Ann Int Med 98:577-584, 1983

4. McGovern B, Garan H, Malacoff R, et al: Long-term clinical outcome of ventricular tachycardia of fibrillation treated with amiodarone. Am J Cardiol 53:1558-1563, 1984

5. Haffajee CI, Love JC, Canada AT, et al: Clinical pharmacokinetics and efficacy of amiodarone for refractory tachyarrhythmias. Circulation 67:1347-1355, 1983

6. Waxman HL, Groh WC, Marchlinski FE, et al: Amiodarone for control of sustained ventricular tachyarrhythmia: Clinical and electrophysiologic effects in 51 patients. Am J Cardiol 50:1066-1074, 1982

7. Hamer AW, Finderman WB, Peter T, et al: Disparity between the clinical and electrophysiologic effects of amiodrone in the treatment of recurrent ventricular tachyarrhythmias. Am Heart J 102:992-1000, 1981

8. Morady F, Sauve MJ, Malone P, et al: Long-term efficacy and toxicity of high-dose amiodarone therapy for ventricular tachycardia or ventricular fibrillation. Am J Cardiol 52:975-979, 1983

9. Podrid PJ, Lown B: Amiodarone therapy in symptomatic, sustained refractory atrial and ventricular tachyarrhythmias. Am Heart J 101:374-379, 1981

10. Naccarelli GV, Fineberg NS, Zipes DP, et al: Amiodarone: Risk factors for recurrence of symptomatic ventricular tachycardia identified at electrophysiologic study. J Am Coll Cardiol 6:814-821, 1985

11. Garson A, Gillette PC, McVey P, et al: Amiodarone treatment of critical arrhythmias in children and young adults. J Am Coll Cardiol 4:749-755, 1984

12. Fogoros RN, Anderson KP, Winkle RA, et al: Amiodarone: Clinical efficacy and toxicity in 96 patients with recurrent, drug refractory arrhythmias. Circulation 68:8894. 1983

13. Horowitz LN, Greenspan AM, Spielman SR, et al: Usefulness of electrophysiologic testing in evaluation of amiodarone therapy for sustained ventricular tachyarrhythmias associated with coronary heart disease. Am J Cardiol 55:367-371, 1985

14. Veltri EP, Reid PR, Platia EV, et al: Results of late programmed electrical stimulation and long-term electrophysiologic effects of amiodarone therapy in patients with refractory ventricular tachycardia. Am J Cardiol 55:375-379, 1985 
15. Wellens HJJ, Brugada $P$, Abdollah $\mathrm{H}$, et al: A comparison of the electrophysiologic effects of intravenous and oral amiodarone in the same patient. Circulation 69:120-124, 1984

16. Rakita L, Sobol SM: Amiodarone in the treatment of refractory ventricular arrhythmias. JAMA 250:1293-1295, 1983

17. Kaski JC, Girotti LA, Messuti H, et al: Long-term management of sustained, recurrent symptomatic ventricular tachycardia with amiodarone. Circulation 64:273-278, 1981

18. Kadish AH, Marchlinski FE, Josephson ME, et al: Amiodarone: Correlation of early and late electrophysiologic studies with outcome. Am Heart J 112:1134-1140, 1986

19. Charlier R: Cardiac actions in the dog of a new antagonist of adrenergic excitation which does not produce competitive blockade of adrenoceptors. $\mathrm{Br}$ J Pharmacol 39:668-674, 1970

20. Charlier R, Deltour G, Baudine A, et al: Pharmacology of amiodarone, an anti-anginal drug with a new biological profile: Arzneimittelforschung 18:1408-1417, 1968

21. Singh BN, Vaughn-Williams EM, et al: A third class of anti-arrhythmic action. Effects on atrial and ventricular intracellular potentials, and other pharmacological actions on cardiac muscle, of MJ 1999 and $\mathrm{AH} \mathrm{3474.} \mathrm{Br} \mathrm{J} \mathrm{Pharmacol}$ 39:675-687, 1970

22. Vaughn-Williams EM: A classification of antiarrhythmic drugs reassessed after a decade of new drugs. J Clin Pharmacol 24:129-147, 1984

23. Mason JW, Hondeghem LM, Katzung BG: Amiodarone blocks inactivated cardiac sodium channels. Furo I Physiol 396:79-81, 1983

24. Mason JW, Hondeghem LM, Katzung Bertram G, et al: Block of inactivated sodium channels and of depolarization-induced automaticity in guinea pig papillary muscle by amiodarone. Circ Res 55:277-285, 1984

25. Yabek SM, Kato R, Singh BN, et al: Acute effects of amiodarone on the electrophysiologic properties of isolated neonatal and adult cardiac fibers. J Am Coll Cardiol 5:11091115,1985

26. Hondeghem LM, Katzung BG: Time-and-voltagedependent interactions of antiarrhythmic drugs with cardiac sodium channels. Biochim Biophys Acta 472:373-398, 1977

27. Hondeghem LM, Katzung BG: Test of a model of antiarrhythmic drug action: effects of quinidine and lidocaine on myocardial conduction. Circulation 61:1217-1224, 1980

28. Yabek SM, Kato R, Singh BN: Effects of amiodarone and its metabolite, desethylamiodarone, on the electrophysiologic properties of isolated cardiac muscle. J Cardiovasc Pharmacol 8:197-207, 1986

29. Morady F, DiCarlo LA, Baerman JM, et al: Ratcdependent effects of intravenous lidocaine, procainamide and amiodarone on intraventricular conduction. J Am Coll Cardiol 6:179-185, 1985

30. Morady F, DiCarlo LA, Krol RB, et al: Acute and chronic effects of amiodarone on ventricular refractoriness, intraventricular conduction and ventricular tachycardia induction. Am Coll Cardiol 7:148-156, 1986

31. Goupil N, Lenfant J; The effects of amiodarone on the sinus node activity of the rabbit heart. Euro $J$ Pharmacol 39:23-31, 1976

32. Gloor HO, Urthaler F, James, TN: Acute effects of amiodarone upon the canine sinus node and atrioventricular junctional region. Am Society Clin Invest 71:1457-1466, 1983

33. Bacq ZM, Blakeley GH, Summers RJ: The effects of amiodarone, an alpha and beta receptor antagonist, on adrenergic transmission in the cat spleen. Biochem Pharmacol 25:1195-1199, 1976

34. Polster $\mathbf{P}$, Broekhuysen $\mathrm{J}$ : The adrenergic antagonism of amiodarone. Biochem Pharmacol 25:131-134, 1976

35. Singh BN, Phil D, Nademanee K: Amiodarone and thyroid function: Clinical implications during antiarrhythmic therapy. Am Heart J 106:857-868, 1983

36. Zipes DP, Prystowsky EN, Heger JJ: Amiodarone: Electrophysiologic actions, pharmacokinetics and clinical effects. J Am Coll Cardiol 3:1059-1071, 1984

37. Latham KR, Sellitti DF, Goldstein RE: Interaction of amiodarone and desethyl amiodarone with nuclear thyroid hormone receptors. J Am Coll Cardiol 5:466, 1985 (abstr)

38. Polikar R, Goy JJ, Schlapper J, et al: Effect of oral triiodo thyronine during amiodarone treatment for ventricular premature complexes. Am J Cardiol 58:987, 1986

39. Meese R, Smithermantc, Croft $\mathrm{CH}$, et al: Effect of peripheral thyroid hormone metabolism on cardiac arrhythmias. Am J Cardiol 55:849-851, 1985

40. Andreasen F, Agerback $H$, Bjerregaard $P$, et al: Pharmacokinetics of amiodarone after intravenous and oral administration. Euro J Clin Pharmacol 19:293-299, 1981

41. Latini R, Tognoni G, Kates RE: Clinical pharmacokinetics of amiodarone. Clin Pharmacol 9:136-156, 1984

42. Anastasiou-Nana M, Levis GM, Moulopoulos S: Pharmacokinetics of amiodarone after intravenous and oral administration. Int J Clin Pharmacol Ther Toxicicol 20:524529,1982

43. Haffajee CI, Love JC, Canada AT, et al: Clinical pharmacokinetics and efficacy of amiodarone for refractory tachyarrhythmias. Circulation 67:1347-1355, 1983

44. Maggioni AP, Maggi A, Volpi A, et al: Amiodarone distribution in human tissues after sudden death during Holter recording. Am J Cardiol 52:217-218, 1983

45. Riva E, Gerna $M$, Neyroz $P$, et al: Pharmacokinetics of amiodarone in rats. J Cardiovasc Pharmacol 4:270-275, 1982

46. Debbas NMG, Bexton RS, duCailar C, et al: Relation between myocardial amiodarone concentration and QT interval. Br Heart J 57:316-320, 1983

47. Latini R, Connolly SJ, Kates RE: Myocardial disposition of amiodarone in the dog. J Pharmacol Exp Ther 224: 603-608, 1983

48. Holt DW, Tucker GT, Jackson PR, et al: Amiodarone pharmacokinetics. Am Heart J 106:840-846, 1983

49. Riva E, Aarons L, Latini R, et al: Amiodarone kinetics after single i.v. bolus and multiple dosing in healthy volunteers. Euro J Clin Pharmacol 27:491-494, 1984

50. Talajic M, DeRoode MR, Nattel S: Comparative electrophysiologic effects of intravenous amiodarone and desethylamiodarone in dogs: Evidence for clinically relevant activity of the metabolite. Circulation 75:265-271, 1987

51. Gough WB, Zeiler RH, Barreca P, et al: Hypotensive action of commercial intravenous amiodarone and polysorbate 80 in dogs. J Cardiovasc Pharmacol 4:375-380, 1982

52. Bopp P, Rasoamanambelo L, Crevoisier, JL, Barthel- 
emy JC, et al: Acute hemodynamic effects of intravenous amiodarone in patients with coronary artery disease. J Cardiovasc Pharmacol 7:286-289, 1985

53. Kosinski EJ, Albin JB, Young E, et al: Hemodynamic effects of intravenous amiodarone. J Am Coll Cardiol 4:565570,1984

54. Remme WJ, Van Hoogenhuyze DCA, Krauss XH, et al: Acute hemodynamic and antiischemic effects of intravenous amiodarone. Am J Cardiol 55:639-644, 1985

55. Schwartz A, Shen E, Morady F, et al: Hemodynamic effects of intravenous amiodarone in patients with depressed left ventricular function and recurrent ventricular tachycardia. Am Heart J 106:848-855, 1983

56. Saksena S, Rothbart ST, Shah Y, et al: Clinical efficacy and electropharmacology of continuous intravenous amiodarone infusion and chronic oral amiodarone in refractory ventricular tachycardia. Am J Cardiol 54:347-352. 1984

57. Touboul P, Atallah G, Gressard A, et al: Effects of amiodarone on sinus node in man. $\mathrm{Br}$ Heart $\mathrm{J}$ 42:573-578, 1979

58. Ikeda N, Nademanee K, Kannan R, et al: Electrophysiologic effects of amiodarone: Experimental and clinical observation relative to serum and tissue drug concentrations. Am Heart J 108:890-898, 1984

59. Waleffe A, Bruninx P, Kulbertus HE: Effects of amiodarone studied by programmed electrical stimulation of the heart in patients with paroxysmal re-entrant supraventricular tachycardia. J Electrocardiol 11:253-260, 1978

60. Leak D: Intravenous amiodarone in the treatment of refractory life-threatening cardiac arrhythmias in the critically ill patient. Am Heart J 111:456-462, 1986

61. Horowitz LN, Mattleman SJ, Spielman SR, et al: Intravenous amiodarone loading for ventricular tachycardia. Circulation 66:222, 1982 (abstr)

62. Mostow ND, Rakita L, Vrobel TR, et al: Amiodarone: Intravenous loading for rapid suppression of complex ventricular arrhythmias. J Am Coll Cardiol 4:97-104, 1984

63. Maggioni AP, Volpi A, Cavalli A, et al: Incessant atrioventricular nodal reciprocating tachycardia successfully treated with intravenous amiodarone. Brief Comm 110:159161,1986

64. Holt P, Crick JCP, Davies DW, et al: Intravenous amiodarone in the acute termination of supraventricular arrhythmias. Int J Cardiol 8:67-76, 1985

65. Storelli A, Hndriulo C, Chisena $\mathrm{H}$, et al: Intravenous amiodarone in the therapy of paroxysmal supraventricular tachycardias. G Ital Cardiol 15:290-297, 1985

66. Bucknall CA, Keeton BR, Curry PVL, et al: Intravenous and oral amiodarone for arrhythmias in children. $\mathrm{Br}$ Heart J 56:278-284, 1986

67. Gomes JAC, Kang PS, Hariman RJ, et al: Electrophysiologic effects and mechanisms of termination of supraventricular tachycardia by intravenous amiodarone. Am Heart J 107:214-221, 1984

68. Alboni P, Shantha N, Pirani R, et al: Effects of amiodarone on supraventricular tachycardia involving bypass tracts. Am J Cardiol 53:93-98, 1984

69. Installe E, Schoevaerdts JC, Gadisseux, et al: Intravenous amiodarone in the treatment of various arrhythmias following cardiac operations. J Thorac Cardiovasc Surg 81:302-308, 1981

70. Morady F, Scheinman MM, Shen E, et al: Intravenous amiodarone in the acute treatment of recurrent symptomatic ventricular tachycardia. Am J Cardiol 51:156-159, 1983

71. Alves LE, Rose EP, Cahill TB: Intravenous amiodarone in the treatment of refractory arrhythmias. Critical care Med 13:750-752, 1985

72. Van Hoogenhuyze D, V.D. Burg P, de Wilde A, et al: Acute effects of intravenous amiodarone in patients with complex ventricular dysrhythmias. Am J Cardiol 49:1001, 1982 (abstr)

73. Benaim R, Denizeal JP, Melon J, et al: Les effets antiarythmiques de l'amiodarone injectable. Mel Coeur 69:513-522, 1976

74. Nademanee K, Feld G, Hendrickson J, et al: Does intravenous amiodarone shorten the latency of the onset of antiarrhythmic action of oral amiodarone in ventricular dysrhythmias. J Am Coll Cardiol 1:630, 1983

75. Hariman RJ, Gomes JAC, Kang PS, et al: Effects of intravenous amiodarone in patients with inducible repetitive ventricular responses and ventricular tachycardia. Am Heart J 107:1109-1118, 1984

76. Veltri EP, Reid PR: Sinus arrest with intravenous amiodarone. Am J Cardiol 58:1110-1111, 1986

77. Bertholet M, Dubois C, Materne P, et al: Sudden marked QT prolongation after intravenous administration of amiodarone. Am J Cardiol 52:1361-1362, 1983

78. Veglia L. Scandiffio T, Guerricchio G: "Torsioni di punti" e amiodarone. G Ital Cardiol 8:1025-1209, 1978

79. Benaim R, Uzan C: Les effets antiarythmiques de l'amiodarone injectable (a propos de 153 cas.) Rev Med 19:1959, 1978 (abstr)

80. Barillon A: Colloque sur l'amiodarone. Paris, 1977, Documentation Medicale Labaz, $\mathrm{p} 70$

81. Mostow ND, Vrobel TR, Noon D, et al: Rapid suppression of complex ventricular arrhythmias with highdose oral amiodarone. Circulation 73:1231-1238, 1986

82. Kerin NZ, Blevins RD, Frumin H, et al: Intravenous and oral loading versus oral loading alone with amiodarone for chronic refractory ventricular arrhythmias. Am J Cardiol 55:89-91, 1985

83. Velebit V, Podrid P, Lown B, et al: Aggravation and provocation of ventricular arrhythmias by antiarrhythmic drugs. Circulation 65:886-894, 1982

84. Strasberg B, Scalarovsky S, Erdberg A, et al: Procainamide-induced polymorphous ventricular tachycardia. Am J Cardiol 47:1309-1314, 1981

85. Buxton AE, Josephson ME: Role of electrophysiologic studies in identifying arrhythmogenic properties of antiarrhythmic drugs. Circulation 73:II-67-72, 1986 